\title{
Induced sputum: not only for research but also for better patient management in asthma and COPD
}

\author{
R. Louis \\ Monaldi Arch Chest Dis 2012; 77: 1, 5-7. \\ Department of Pneumology, CHU Liege, GIGAI Research Group, University of Liege, Belgium. \\ Correspondence: R. Louis, Department of Pneumology, CHU Liege, GIGAI ${ }^{3}$ Research Group, University of Liege, Belgium; \\ e-mail:r.louis@chu.ulg.ac.be
}

It has been now twenty years since the first description of induced sputum as a research application in asthma [1,2]. Since then the research application of this technique has really exploded giving rise to an impressive number of publications in the field of asthma and COPD. Overall it is fair to say that asthma is rather an eosinophilic airway disease while COPD patients usually exhibit a massive neutrophilic inflammation [3]. This view is however simplistic and when asthma becomes more severe, eosinophilic inflammation usually coexists with neutrophilic inflammation $[4,5]$. On the other hand, a not negligible contingent of COPD displays an eosinophilic airway inflammation [6].

A lot of studies have measured biochemical compounds in sputum supernatant associated with eosinophilic and neutrophilic inflammation. All these studies can be somehow summarized by saying that eosinophilic airway inflammation is usually associated with raised secretion products from eosinophils like eosinophil cationic prtotein (ECP) and Th2 cytokines like interleukine-5, while neutrophilic inflammation is rather associated with secretion products from neutrophils like myeloperoxidase and the neutrophilic chemokine interleukine-8 [7]. Recent studies have gone further by unravelling the sputum cell gene expression associated with each type of inflammation $[8,9]$.

Sputum has also made it possible to undertake elegant mechanistic studies looking at cellular pharmacology or at biological properties of supernatant. As an example sputum cells can be cultured for $24 \mathrm{~h}$ ex vivo and assessed for their capacity to release cytokine or growth factors [10]. Also the fluid phase was shown to contain chemotactic or anti-apoptotic activity for eosinophils or neutrophils that sometimes correlated to disease severity [11-14].

One of the most important features in COPD and severe asthma is the airway and lung remodelling, the latter being essentially seen in COPD. By definition remodelling is measured on piece of tissues usually obtained by bronchial biopsies performed during a bronchoscopy. Alternatively re- modelling is more and more assessed by fine lung imaging like thin slice chest CT. There has been early attempt to validate some biochemical compounds from sputum supernatant as markers of airway remodelling. Matrix metalloproteases (MMPs) and their physiological inhibitors (TIMPs) are keys in regulating the metabolism of conjunctive tissue. Among those proteins emphasis has been placed on MMP-9, a matrix metalloprotease with gelatinolytic activity, and TIMP-1, its physiological inhibitor. Both the pro and the activated form of MMP-9 and TIMP-1 were found to be raised in asthmatics and COPD as compared to healthy subjects [15]. Vignola et al. have shown the ratio MMP-9/TIMP-1 to be related airway calibre assessed by $\mathrm{FEV}_{1}$ [16]. In stable asthmatics and patients suffering from chronic bronchitis they showed that the lower the ratio the lower the $\mathrm{FEV}_{1}$ suggesting that an excess of TIMP-1 would favour tissues remodelling [17]. In this issue of the journal Dar et al. confirmed previous results of Vignola et al. by showing raised sputum levels of MMP9 and TIMP-1 in sputum from asthmatics and COPD but a clearly reduced ratio MMP-9/TIMP-1 when disease severity increases [18]. Their study is a further validation of the utility of this ratio as a marker of airway remodelling since they found a relationship between the progression of the remodelling on chest $\mathrm{CT}$ and a low ratio value.

Conversely high MMP-9/TIMP-1 ratio has been found in acute asthma [19] and following experimental allergenic exposure [20]. This suggests that flare up of airway inflammation is actually associated with an enhanced local gelatinolytic activity. Thus the picture may be different in acute conditions as opposed to the stable state of severe chronic disease. Whether a low MMP-9/TIMP-1 ratio would be predictive of an accelerated lung decline in asthma and COPD is an interesting question that should be addressed in a prospective longitudinal study.

Induced sputum has been instrumental in the development of asthma and COPD phenotypes based on the nature of the airway cellular inflammation $[21,22]$. Based on our experience in a 
large cohort of asthmatic patients it appears that paucigranulocytic and eosinophilic $(>3 \%)$ asthma are the two most frequent phenotypes each accounting for approximately $40 \%$ of patients while neutrophilic (> 76\%) asthma only represents roughly $15-16 \%$ of asthmatics and mixed granulocytic was rather rare $(<5 \%)$. In contrast the dominant pattern in COPD is the neutrophilic pattern $[23,24]$ even if a small fraction of COPD exhibits eosinophilic inflammation associated with sign of mast cell activation reminiscent of asthma pathophysiology [25]. The nature of the cellular inflammation is likely to depend on the stimuli involved, allergens being the most conspicuous factor for eosinophilic inflammation whereas neutrophilic inflammation is most frequently induced by infection or pollutant exposure [26]. Interestingly targeting the extent of eosinophilic inflammation by adjusting the dose of inhaled or systemic corticoids was shown to improve asthma [27, 28] or COPD [29] control by reducing the number of exacerbations. By contrast the neutrophilic inflammation in asthma or COPD is rather insensitive to corticoids but may be attenuated by regular intake of macrolides [30].

Induced sputum has been shown to be a valid method to collect cells during asthma [31] and COPD [32-34] exacerbations. Most of the time, this disease state is associated with an amplification of the baseline inflammatory process. Not surprisingly flares up of eosinophilic or neutrophilic inflammation have been reported in several studies. The nature of the inflammation is more dependent of the etiologic agent causing the exacerbation than of the disease itself. However, it was reported that some agents such as viruses may cause both types of inflammation [32]. In this issue of the journal Zanini A. et al. report on the case of one COPD stage III successively developing two exacerbations featuring a heavily neutrophilic inflammation in the first case and a moderate sputum eosinophilia in the second one [35]. In both cases the patient recovered after treatment but interestingly the authors adapted their treatment strategy according to the sputum cellular profile. Assuming an infectious origin in the first case they prescribed antibiotics without corticoids when sputum was neutrophilic while they choose to go for a course of systemic corticoids when sputum analysis revealed high eosinophil counts. The origin of the flare up of sputum eosinophilia in COPD is unclear and there was no history of allergy in the present case. Virus infection was a plausible cause. Eosinophilic inflammation in acute exacerbation of chronic bronchitis was already reported almost twenty years ago [36]. It is thus important to realize that exacerbations of COPD are not always neutrophilic and that raised eosinophilia may justify a course of systemic corticoids perhaps not indicated when inflammation is purely neutrophilic. Whether corticoids are really useless when inflammation is heavily neutrophilic and antibiotics useless when inflammation is strongly eosinophilic, is a key issue. Although case reports are of great values in generating hypotheses there is a need to un- dertake prospective studies to definitely answer this crucial question. Until we have the response it is probably careful to combine systemic corticoids and antibiotics to treat exacerbations of severe COPD.

\section{References}

1. Fahy JV, Liu J, Wong H, Boushey HA. Cellular and biochemical analysis of induced sputum from asthmatic and from healthy subjects. Am Rev Respir Dis 1993; 147: 1126-31.

2. Pin I, Gibson PG, Kolendowicz R, et al. Use of induced sputum cell counts to investigate airway inflammation in asthma. Thorax 1992; 47: 25-9.

3. Ronchi MC, Piragino C, Rosi E, Amendola M, Duranti R, Scano G. Role of sputum differential cell count in detecting airway inflammation in patients with chronic bronchial asthma or COPD. Thorax 1996; 51: 1000-4.

4. Jatakanon A, Uasuf C, Maziak W, Lim S, Chung KF, Barnes PJ. Neutrophilic inflammation in severe persistent asthma. Am J Respir Crit Care Med 1999; 160: 1532-9.

5. Louis R, Lau LC, Bron AO, Roldaan AC, Radermecker M, Djukanovic R. The relationship between airways inflammation and asthma severity. Am J Respir Crit Care Med 2000; 161: 9-16.

6. Brightling CE, Monteiro W, Ward R, et al. Sputum eosinophilia and short-term response to prednisolone in chronic obstructive pulmonary disease: a randomised controlled trial. Lancet 2000; 356: 1480-5.

7. Bakakos P, Schleich F, Alchanatis M, Louis R. Induced sputum in asthma: from bench to bedside. Curr Med Chem 2011; 18: 1415-22.

8. Baines KJ, Simpson JL, Wood LG, Scott RJ, Gibson PG. Transcriptional phenotypes of asthma defined by gene expression profiling of induced sputum samples. $J$ Allergy Clin Immunol 2011; 127: 153-60, 160.

9. Hastie AT, Moore WC, Meyers DA, et al. Analyses of asthma severity phenotypes and inflammatory proteins in subjects stratified by sputum granulocytes. J Allergy Clin Immunol 2010; 125: 1028-36.

10. Manise M, Schleich F, Gusbin N, Godinas L, Henket M, Antoine N, Corhay JL, Louis R. Cytokine production from sputum cells and blood leukocytes in asthmatics according to disease severity. Allergy 2010; 65: 889-96.

11. Beeh KM, Kornmann O, Buhl R, Culpitt SV, Giembycz MA, Barnes PJ. Neutrophil chemotactic activity of sputum from patients with COPD: role of interleukin 8 and leukotriene B4. Chest 2003; 123: 1240-7.

12. Corhay JL, Hemelaers L, Henket M, Sele J, Louis R. Granulocyte chemotactic activity in exhaled breath condensate of healthy subjects and patients with COPD. Chest 2007; 131: 1672-7.

13. Duncan CJ, Lawrie A, Blaylock MG, Douglas JG, Walsh GM. Reduced eosinophil apoptosis in induced sputum correlates with asthma severity. Eur Respir $J$ 2003; 22: 484-90.

14. Louis R, Shute J, Biagi S, et al. Cell infiltration, ICAM1 expression, and eosinophil chemotactic activity in asthmatic sputum. Am J Respir Crit Care Med 1997; 155: 466-72.

15. Cataldo D, Munaut C, Noel A, et al. MMP-2- and MMP-9-linked gelatinolytic activity in the sputum from patients with asthma and chronic obstructive pulmonary disease. Int Arch Allergy Immunol 2000; 123: 259-67.

16. Vignola AM, Riccobono L, Mirabella A, et al. Sputum metalloproteinase-9/tissue inhibitor of metalloproteinase-1 ratio correlates with airflow obstruction in asthma and chronic bronchitis. Am J Respir Crit Care Med 1998; 158: 1945-50. 
17. Vignola AM, Paganin F, Capieu L, et al. Airway remodelling assessed by sputum and high-resolution computed tomography in asthma and COPD. Eur Respir $J$ 2004; 24: 910-7.

18. Ahmad Dar K, Shahid M, Mubeen A, et al. The role of noninvasive methods in assessing airway inflammation and structural changes in asthma and COPD. Monaldi Arch Chest Dis 2012; 77: 8-18.

19. Tanaka H, Miyazaki N, Oashi K, Tanaka S, Ohmichi M, Abe S. Sputum matrix metalloproteinase-9: tissue inhibitor of metalloproteinase-1 ratio in acute asthma. $J$ Allergy Clin Immunol 2000; 105: 900-5.

20. Cataldo DD, Bettiol J, Noel A, Bartsch P, Foidart JM, Louis R. Matrix metalloproteinase-9, but not tissue inhibitor of matrix metalloproteinase-1, increases in the sputum from allergic asthmatic patients after allergen challenge. Chest 2002; 122: 1553-9.

21. Brightling CE. Clinical applications of induced sputum. Chest 2006; 129: 1344-8.

22. Wardlaw AJ, Silverman M, Siva R, Pavord ID, Green R. Multi-dimensional phenotyping: towards a new taxonomy for airway disease. Clin Exp Allergy 2005; 35: 1254-62.

23. Moermans C, Heinen V, Nguyen M, et al. Local and systemic cellular inflammation and cytokine release in chronic obstructive pulmonary disease. Cytokine 2011; 56: 298-304.

24. Singh D, Edwards L, Tal-Singer R, Rennard S. Sputum neutrophils as a biomarker in COPD: findings from the ECLIPSE study. Respir Res 2010; 11: 77.

25. Louis RE, Cataldo D, Buckley MG, et al. Evidence of mast-cell activation in a subset of patients with eosinophilic chronic obstructive pulmonary disease. Eur Respir J 2002; 20: 325-31.

26. Pavord ID, Birring SS, Berry M, Green RH, Brightling CE, Wardlaw AJ. Multiple inflammatory hits and the pathogenesis of severe airway disease. Eur Respir $J$ 2006; 27: 884-8.

27. Green RH, Brightling CE, McKenna S, et al. Asthma exacerbations and sputum eosinophil counts: a randomised controlled trial. Lancet 2002; 360: 1715-21.

28. Jayaram L, Pizzichini MM, Cook RJ, et al. Determining asthma treatment by monitoring sputum cell counts: effect on exacerbations. Eur Respir J 2006; 27: 483-94.

29. Siva R, Green RH, Brightling CE, et al. Eosinophilic airway inflammation and exacerbations of COPD: a randomised controlled trial. Eur Respir J 2007; 29: 906-13.

30. Simpson JL, Powell H, Boyle MJ, Scott RJ, Gibson PG. Clarithromycin targets neutrophilic airway inflammation in refractory asthma. Am J Respir Crit Care Med 2008; 177: 148-55.

31. Wark PA, Gibson PG, Johnston SL. Exacerbations of asthma: addressing the triggers and treatments. Monaldi Arch Chest Dis 2001; 56: 429-35.

32. Papi A, Bellettato CM, Braccioni F, et al. Infections and airway inflammation in chronic obstructive pulmonary disease severe exacerbations. Am J Respir Crit Care Med 2006; 173: 1114-21.

33. Seemungal T, Harper-Owen R, Bhowmik A, et al. Respiratory viruses, symptoms, and inflammatory markers in acute exacerbations and stable chronic obstructive pulmonary disease. Am J Respir Crit Care Med 2001; 164: 1618-23.

34. Delmastro M, Balbi B. Acute exacerbations of COPD: is inflammation central to prevention and treatment strategies? Monaldi Arch Chest Dis 2002; 57: 293-6.

35. Zanini A, Della Patrona S, Facchini AL, Spanevello A. Induced sputum in the management of COPD: clinical implications. Monaldi Arch Chest Dis 2012; 77: 23-5.

36. Saetta M, Di Stefano A, Maestrelli P, et al. Airway eosinophilia in chronic bronchitis during exacerbations. Am J Respir Crit Care Med 1994; 150: 1646-52.

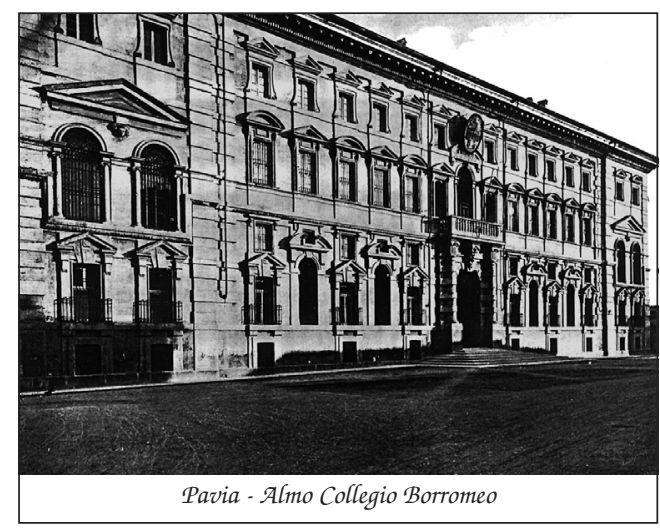

